\title{
Health behaviours associated with video gaming in adolescent men: a cross- sectional population-based MOPO study
}

Tuulia Puolitaival ${ }^{1,2 \dagger}$, Mirjam Sieppi ${ }^{1,2 \dagger}$, Riitta Pyky ${ }^{1,2,3,4^{*}}$, Heidi Enwald ${ }^{3,5}$, Raija Korpelainen ${ }^{1,2,3}$ and Marjukka Nurkkala ${ }^{1,2,3}$

\begin{abstract}
Background: Playing video games, a form of sedentary behaviour, is associated with poor well-being and increased risk of morbidity due to chronic disease. However, the association between health behaviours and video gaming is poorly understood. The purpose of this population-based study was to reveal the differences in dietary habits and physical activity for adolescent men with high amount of video games on weekdays, as compared to their peers who play less often.

Methods: Seven hundred ninety-six adolescent men (age: mean $=17.8, \mathrm{SD}=0.6$ ) attended compulsory conscription for military service in 2013 and completed a questionnaire regarding the amount and frequency of their video gaming. They also participated in a medical examination and underwent physiological measurements. The participants who played video games more than $3 \mathrm{~h} / \mathrm{d}$ on weekdays were compared with those who played $3 \mathrm{~h} / \mathrm{d}$ or less. The association between health behaviours and the amount of playing video gaming was analysed using multivariable logistic regression analysis.

Results: $24.1 \%(n=192)$ of the participants reported video gaming in excess of $3 \mathrm{~h} / \mathrm{d}$. This group had higher incidence of having low physical fitness, having poor eating habits, and being obese. No differences were found in smoking or alcohol drinking habits. Other factors, including low leisure-time physical activity $(\mathrm{OR}=1.94 ; 95 \% \mathrm{Cl}, 1.29-2.91)$, low consumption of vegetables and fruits $(\mathrm{OR}=0.83 ; 95 \% \mathrm{Cl}, 0.72-0.97)$, high consumption of sweetened soft drinks $(\mathrm{OR}=1.28 ; 95 \% \mathrm{Cl}$, 1.06-1.55) and high amount of sitting time $(\mathrm{OR}=1.40 ; 95 \% \mathrm{Cl}, 1.28-1.52)$, explained one-fourth of the difference.

Conclusion: In this population-based study, adolescent men who played video games a lot on weekdays had lower physical fitness, were more often obese, and had poorer dietary habits, as compared to their peers who played less often. Because playing video games typically adds to a person's total sedentary time, this activity may be associated with adverse health outcomes at a very young age - especially in combination with poor health behaviours. The results of this study can be utilized to promote health interventions targeted at adolescent men so as to raise their awareness of the disadvantages of excessive video gaming.
\end{abstract}

Keywords: Video games, Physical activity, Eating habits, Male, Adolescent, Health behaviour, Gaming

\footnotetext{
* Correspondence: riitta.pyky@odl.fi

Tuulia Puolitaival and Mirjam Sieppi shared contribution.

'Department of Sports and Exercise Medicine, Oulu Deaconess Institute

Foundation sr, Albertinkatu 18A, P.O. Box 365, 90100 Oulu, Finland

${ }^{2}$ Center for Life Course Health Research, Faculty of Medicine, University of

Oulu, P.O. Box 5000, 90014 Oulu, Finland

Full list of author information is available at the end of the article
}

(c) The Author(s). 2020 Open Access This article is licensed under a Creative Commons Attribution 4.0 International License, which permits use, sharing, adaptation, distribution and reproduction in any medium or format, as long as you give appropriate credit to the original author(s) and the source, provide a link to the Creative Commons licence, and indicate if changes were made. The images or other third party material in this article are included in the article's Creative Commons licence, unless indicated otherwise in a credit line to the material. If material is not included in the article's Creative Commons licence and your intended use is not permitted by statutory regulation or exceeds the permitted use, you will need to obtain permission directly from the copyright holder. To view a copy of this licence, visit http://creativecommons.org/licenses/by/4.0/. The Creative Commons Public Domain Dedication waiver (http://creativecommons.org/publicdomain/zero/1.0/) applies to the data made available in this article, unless otherwise stated in a credit line to the data. 


\section{Background}

According to the current evidence, regular physical activity in adolescence is associated with many health benefits [1]. In addition, the evidence suggests that excessive sedentary behaviour, especially sitting, is harmful to the health of young people and it may increase the risk of cardiovascular risks in adolescence $[2,3]$. Sedentary behaviour has been defined as any waking behaviour that is characterized by an energy expenditure $\leq 1.5$ metabolic equivalents (METs) and that involves a sitting, reclining, or lying posture [4]. Common sedentary behaviours include screen-time activities (e.g., watching television or other video content, playing video games, and using computers) [5], as well as driving and reading. A video game is an interactive game that is played on a digital device and that contains visual and (often) audio components; a video game can be based on a story [6].

Traditional television watching has declined in the past 10 years, and it has been replaced by other screen-based activities [7]. In their leisure time, adolescents (aged 1318) use screen-based media, on average, $6 \mathrm{~h} 40 \mathrm{~min}$ per day [8]. In a previous study, 15-18 years male and female adolescents reported to play video games approximately $13.0 \mathrm{~h} /$ wk. [9] The other self-reported results are similar for Finnish sample with young adults (mean age 18.7 years) playing video games $11.5 \mathrm{~h} /$ week, and for German population-based sample, with adolescents (mean age 15.3 years) playing video games $141 \mathrm{~min} / \mathrm{d}$ $[10,11]$. In these all studies, boys played significantly more than girls.

However, it is worth remembering that sedentary behaviour is not a synonym for physical inactivity, which refers to physical activity levels that do not meet recommendations [12]. According to the World Health Organization's Global Recommendations on Physical Activity for Health, children aged 5-17 should engage in at least 60 min of moderate to vigorous physical activity every day, and most of this activity should be aerobic [13]. Vigorous-intensity activities should be incorporated, including those that strengthen muscle and bone, at least 3 times per week. According to the Health Behaviour in School-aged Children study, only $17 \%$ of Finnish boys at age 15 reported at least one hour daily moderate to vigorous physical activity [14]. Instead, of 15-24 years old European men, $32 \%$ reported moderate and $27 \%$ vigorous physical activity in 4-7 days during the past week [15].

The Physical Activity Guidelines for Americans account for daily sedentary behaviour [16]. The Canadian movement guidelines for children and youth include recommendations for physical activity, sedentary behaviour, and sleep; for example, for children aged 5-17, screen time should be limited to $2 \mathrm{~h} / \mathrm{d}$ [17]. The Physical Activity Guidelines for Americans also emphasize that reducing sitting time and increasing movement have enormous benefits for everyone-regardless of sex, age, ethnicity, race, or current fitness level [16].

The proportion of overweight adolescents has increased, which is problematic because adolescence weight problems often lead to adult obesity and related health problems [18, 19]. Low physical activity and high levels of sedentary behaviour are also associated with increased body mass index (BMI) and junk-food consumption [2, 20]. In addition, high screen time is associated with high consumption of energydense and micronutrient-poor products, as well as with low consumption of vegetables and fruits [21]. However, the association between childhood obesity and increased screen time is unclear. According to other researchers, among children aged 9-16, more time watching television and playing video games, as well as more total screen time, are associated with higher BMI for girls but not for boys [5].

The current evidence regarding the association between video gaming and health behaviours (eg, physical activity and dietary habits) is scant. In order to decrease the sedentary behaviour among youth, different patterns of sedentary behaviour should be identified and studied how those patterns are associated with physical activity and other health behaviour. Thus, this study is intended to reveal any existing differences in dietary habits and physical activity among adolescent men who play more video games than their peers do. The hypothesis of the study is that those who play more video games are less physically active and have less healthful eating habits.

\section{Methods}

\section{Study design and setting}

This cross-sectional study is based on a populationbased study MOPO of all conscription-aged adolescent men in the years 2009-2013 in the city of Oulu, Finland. The "MOPO" is a slang word for a young recruit, and the study was named along that. In that country, conscription occurs every year and is compulsory for all male citizens in the year when they turn 18. The participants completed a medical examination before their conscription. They then filled out a questionnaire on their health, health behaviours, socioeconomic factors, and gaming habits. They also underwent physiological measurements. This study is based on the data collected during 2013 because the questionnaire included items on sedentary video gaming in that year. In 2013, 1265 adolescent men in Oulu participated in conscription, of whom 1023 (80.9\%) completed the questionnaire. Thus, the data analysis for this study includes only those who reported their daily amount of video gaming $(n=796$, $62.9 \%)$, of which $578(72.6 \%)$ took part in the physiological measurements.

The study was conducted in accordance with the 1964 Declaration of Helsinki and was approved by the Ethical Committee of Northern Ostrobothnia Hospital District 
(ETTM123/2009). The participants provided written informed consent after they received a complete description of the study. The subjects had the right to refuse to participate in the study or to withdraw from it, and the study did not affect either the participants' military service or their future healthcare.

\section{Questionnaire}

We mostly utilized validated and widely used questions in this study. Some questions were developed for the purpose of the study. The amount of video gaming was measured with open-ended questions separately for multiplayer and single-player games: "How many hours per day, on average, do you play games on weekdays?". Because we supposed that playing on weekdays sorts out a lot and moderately players from each other, the total hours were summed and divided into tertiles. The highest tertile was defined as playing $>3 \mathrm{~h} / \mathrm{d}$ on weekdays and labelled $P V>3$, and the other two tertiles were combined (thus defined as playing $\leq 3 \mathrm{~h} / \mathrm{d}$ on weekdays) and labelled $P V \leq 3$. Video game playing on weekends and days off was determined through similar questions, which was used in the characteristics (Table 1).

The amount of leisure-time physical activity was measured with the following question: "How often, and for how long, do you participate in light or brisk physical activity or exercise during your leisure time?" Brisk physical activity was defined as causing at least some sweating and heavy breathing, and light physical activity was defined as causing no sweating or heavy breathing. This question had 6 response options for frequency (once per month or less [score 0 in calculation], 2-3 times per month [0.5], once per week [1], 2-3 times per week [2.5], 4-6 times per week [5], and daily [7]), as well as 6 options for duration (not at all [0 $\mathrm{min}]$, less than $20 \mathrm{~min}$ [10], 20-39 $\mathrm{min}$ [30], 40-59 $\mathrm{min}$ [45], 60-90 $\mathrm{min}$ [75], and $>90 \mathrm{~min}$ [90]) [22]. Weekly averages in MET minutes for light or brisk physical activity were calculated by multiplying the physical activity's volume (duration $[\mathrm{min}] \times$ frequency) by its intensity (light physical activity $=3$ METs and brisk physical activity $=5$ METs) [23]. The resulting values were then summed, and a dichotomous variable with a cut-off point of 500 MET min was created from the aggregate MET min values (from the Physical Activity Guidelines for Americans) [24].

The amount of leisure time spent sitting each day was determined with the following question: "Approximately how much time do you spend sitting per day, outside of school and work (for example, watching television, reading, using a computer, playing video games, or using the Internet)?" The participants reported this in hours, and the results were classified as a two-class variable (nonsedentary vs. sedentary) with a cut-off point of $5 \mathrm{~h} / \mathrm{d}$ [25], and sitting hours were used as a continuous variable in the logistic regression analysis.

Physical fitness was evaluated with the question "How fit are you, as compared to your peers?" The response options were on a 5-point scale from 1 (significantly poorer) through 5 (significantly better). The values of 1 and 2 were combined as poorer, and the values of 3-5 were combined as similar or better, resulting in a twoclass variable. Similarly, self-rated health was investigated with the following question: "What is the state of your health?" The response options were on a 5-point scale from 1 (good) through 5 (poor). Again, the values from 1 to 3 were combined (good or average), as were the values of 4 and 5 (poor).

Dietary habits were determined with the following question about the mean consumption of various foods: "How often during the preceding week did you consume the following foods or drinks?" The answers were 1 (never), 2 (1-2 days per week), 3 (3-5 days per week), and 4 (6-7 days per week), and the frequency was recoded using the following conversion: never $=0 \mathrm{~d} / \mathrm{wk} ., 1-2$ days per week $=1.5 \mathrm{~d} /$ wk., $3-5$ days per week $=4 \mathrm{~d} / \mathrm{wk}$., and 6-7 days per week $=6.5 \mathrm{~d} / \mathrm{wk}$. [26, 27] The mean frequency of consuming fresh vegetables, cooked vegetables, and fruits was combined into one variable by summing the recoded frequencies for each and then dividing by three. The mean consumption of junk food was similarly the average of the frequencies for salty foods and sweet foods. Salty foods were defined as including "pizza and kebabs," "savoury pastries (burgers, pies, etc.)," and "salty snacks (crisps, etc.)." Sweet foods were defined as including "sweet pastries (buns, biscuits, etc.)" and "chocolate and other sweets." The mean consumption of sweetened soft drinks was based on the average of the frequencies for sugary or artificially sweetened soft drinks and energy drinks. The participants also answered whether they usually eat breakfast (yes or no).

Alcohol intake was measured with this question: "How often do you drink six or more servings of alcohol at once?" The response options were on a 6-point scale from 1 (never) through 6 (daily or almost daily). A twograde variable was formed to measure binge drinking (defined as 6 servings or more in a day at least once per week) $[25,28]$. The participants also reported whether they currently smoked or used snuff (yes or no for each).

\section{Physiological measurements}

Each participant's height was measured (with $0.5-\mathrm{cm}$ precision) using a wall-mounted measuring tape. Similarly, waist circumference was measured (to the nearest $1 \mathrm{~cm}$ ) along the midline between the lowest rib and the iliac crest. Body composition was measured using weight (with $0.1-\mathrm{kg}$ accuracy), fat-free mass (at $0.1-\mathrm{kg}$ accuracy), and percentage body fat; the latter was measured with 
Table 1 Characteristics of the population-based sample of adolescent men based on amount of video gaming on weekdays

\begin{tabular}{|c|c|c|c|c|c|}
\hline Characteristics & $\mathrm{n}$ & All $(\boldsymbol{n}=796)$ & $\begin{array}{l}\text { Video Gaming } \\
>3 \text { h/day } \\
(\boldsymbol{n}=192)\end{array}$ & $\begin{array}{l}\text { Video Gaming } \\
\leq 3 \mathrm{~h} / \text { day } \\
(\boldsymbol{n}=604)\end{array}$ & $\boldsymbol{P}$ value \\
\hline $\mathrm{Age}^{\mathrm{b}}, \mathrm{y}$ & 792 & $17.9(0.7)$ & $18.1(0.9)$ & $17.9(0.7)$ & .008 \\
\hline Weight, kg & 577 & $73.0(14.1)$ & $75.4(17.8)$ & $72.2(12.6)$ & .102 \\
\hline Height, $\mathrm{cm}$ & 578 & $178.1(6.3)$ & $178.2(7.0)$ & $178.2(6.1)$ & .718 \\
\hline $\mathrm{BMI}^{\mathrm{c}}, \mathrm{kg} / \mathrm{m}^{2}$ & 577 & $23.0(4.3)$ & $23.8(5.5)$ & $22.7(3.8)$ & .107 \\
\hline Underweight (BMI < 18.5), No. (\%) & & $47(8.1)$ & $10(7.5)$ & $37(8.4)$ & .858 \\
\hline Normal weight (18.5-24.9) No. (\%) & & $397(68.8)$ & $88(65.7)$ & $309(69.8)$ & .395 \\
\hline Overweight (BMI 25-29.9) No. (\%) & & $96(16.6)$ & $20(14.9)$ & $76(17.2)$ & .598 \\
\hline Obesity (BMI $\geq 30$ ), No. (\%) & & $37(6.4)$ & $16(11.9)$ & $21(4.7)$ & .008 \\
\hline Body fat, $\%$ & 576 & $16.5(8.4)$ & $19.3(10.0)$ & $15.6(7.6)$ & $<.001$ \\
\hline Waist circumference, $\mathrm{cm}$ & 577 & $82.0(10.4)$ & $84.7(13.2)$ & $81.1(9.1)$ & .011 \\
\hline Muscle mass, \% & 576 & $47.0(4.8)$ & $45.3(5.6)$ & $47.6(4.4)$ & $<.001$ \\
\hline Self-rated health & 776 & & & & .001 \\
\hline Poor, No. (\%) & & $56(7.2)$ & $24(12.8)$ & $32(5.4)$ & \\
\hline Good or average, No. (\%) & & $720(92.8)$ & $164(87.2)$ & $556(94.6)$ & \\
\hline Grip strength, $\mathrm{kg}$ & 576 & $45.0(7.5)$ & $43.8(7.8)$ & $45.4(7.4)$ & .017 \\
\hline $\begin{array}{l}\text { Light and brisk physical activity, median } \\
\text { (interquartile range), MET-min weekly }\end{array}$ & 769 & $1013(413-1875)$ & $615(204-1286)$ & $1148(563-2085)$ & $<.001$ \\
\hline < 500 MET-min, No. (\%) & & $219(28.5)$ & $88(47.3)$ & $131(22.5)$ & $<.001$ \\
\hline$\geq 500$ MET-min, No. (\%) & & $550(71.5)$ & $98(52.7)$ & $452(77.5)$ & \\
\hline Aerobic fitness (Polar Fitness Test) $\mathrm{mL} / \mathrm{min} / \mathrm{kg}$ & 563 & $52.9(7.1)$ & $50.4(6.6)$ & $53.7(7.1)$ & $<.001$ \\
\hline Poor self-rated physical fitness, No. (\%) & 781 & $190(24.3)$ & $84(44.4)$ & $106(17.9)$ & $<.001$ \\
\hline Sitting during leisure time, $\mathrm{h} / \mathrm{d}$ & 762 & $4.2(2.3)$ & $5.8(2.4)$ & $3.7(2.0)$ & $<.001$ \\
\hline$\geq 5$ h/d, No. (\%) & & $273(35.8)$ & $129(69.0)$ & $144(25.0)$ & $<.001$ \\
\hline$<5$ h/d, No. (\%) & & $489(64.2)$ & $58(31.0)$ & $431(75.0)$ & \\
\hline \multicolumn{6}{|l|}{ Mean consumption frequency, $d / w k$} \\
\hline Vegetables and fruits & 744 & $2.0(1.5)$ & $1.6(1.5)$ & $2.2(1.5)$ & $<.001$ \\
\hline Sweetened soft drinks and energy drinks & 750 & $1.1(1.0)$ & $1.4(1.2)$ & $1.0(0.9)$ & $<.001$ \\
\hline Salty foods & 747 & $1.0(0.9)$ & $1.1(1.0)$ & $1.0(0.8)$ & .499 \\
\hline Sweet foods & 752 & $1.5(1.1)$ & $1.5(1.2)$ & $1.5(1.0)$ & .455 \\
\hline Usually eats breakfast & 786 & & & & $<.001$ \\
\hline Yes, No. (\%) & & $575(73.2)$ & $118(62.8)$ & $457(76.4)$ & \\
\hline No, No. (\%) & & $211(26.8)$ & $70(37.2)$ & $141(23.6)$ & \\
\hline Smokes currently, No. (\%) & 784 & & & & .851 \\
\hline Yes, No. (\%) & & $209(26.7)$ & $52(27.4)$ & $157(26.4)$ & \\
\hline No, No. (\%) & & $575(73.2)$ & $128(72.6)$ & $437(73.6)$ & \\
\hline Uses snuff currently, No. (\%) & 787 & $189(24.0)$ & $144(23.4)$ & $145(24.2)$ & .846 \\
\hline Binge drinks alcohol $\geq 1 /$ wk., No. (\%) & 786 & $172(21.9)$ & $43(23.1)$ & $129(21.5)$ & .685 \\
\hline
\end{tabular}

${ }^{a}$ This is the $P$ value between groups for video gaming $>3 \mathrm{~h} /$ day vs. video gaming $\leq 3 \mathrm{~h} /$ day

${ }^{b}$ Values are expressed as mean (SD) unless otherwise stated. Some numbers do not match due to missing values

c Variables in bold are part of the binary logistic regression

Abbreviation: $B M I$ body mass index

direct segmental multifrequency bioelectric impedance analysis (InBody720, Biospace Co., Ltd., Seoul, Korea). During the measurements, the subjects stood without shoes or socks and in light indoor clothing. This method has been validated using whole-body dual X-ray absorptiometry. Each participant's percentage of fat-free mass 
was then calculated by dividing muscle mass $(\mathrm{kg})$ by whole-body mass $(\mathrm{kg})$, and each participant's BMI was calculated by dividing weight $(\mathrm{kg})$ by height squared $\left(\mathrm{m}^{2}\right)$.

Each participant's grip strength was measured using a hand dynamometer (Saehan Corporation, Korea). During the test, each subject stood with legs apart and elbows at a $90^{\circ}$ angle, gripping the dynamometer with maximum force. After two attempts using each hand, the best result for each hand was recorded, and the mean of these results was used in the analyses. Aerobic fitness was evaluated using the Polar Fitness Test (Polar Electro, Finland), which was conducted while the subject was at rest for $5 \mathrm{~min}$. This test predicts maximal oxygen uptake $(\mathrm{mL} / \mathrm{min} / \mathrm{kg})$ using resting heart rate, heart-rate variability, sex, age, height, body weight, and self-assessed physical activity [29]. The Polar Fitness Test high accuracy (mean error: $6.5 \%)$ and correlates highly with the ergo-spirometry test as a measure of aerobic condition (0.96) [30].

\section{Statistical analysis}

Statistical analyses were performed using IBM SPSS Statistics for Windows (Version 24.0, Armonk, New York, IBM Corp). An independent-sample $t$ test for continuous variables was used to analyse the statistical significance of the mean differences with $95 \%$ confidence intervals between the PV $>3$ and $P V \leq 3$ groups. Due to the skewed distributions of MET min values, the medians of these values were used, as were the results of a Mann-Whitney $U$ test. Cross-tabulation and the chi squared test were used for the categorical variables. All variables that were significantly associated with video gaming in the univariate analysis were then entered into the binary logistic regression analysis. Video game playing was a dependent variable with categories: $0=$ playing $\leq 3 \mathrm{~h} / \mathrm{d}$ on weekdays and $1=$ playing $>3 \mathrm{~h} / \mathrm{d}$ on weekdays. Because playing video games is a type of sedentary behaviour, leisure-time sitting (as a continuous variable) was entered into the block one with enter selection, and the other associated variables in the second block with forward stepwise (Likelihood Ratio) selection. The level of significance was set at $P<.05$.

\section{Results}

The study population comprised 796 adolescent men with mean age 17.9 (age range 17-22). The PV > 3 group included $192(24.1 \%)$ individuals, who played video games, on average, $5.5(\mathrm{SD}=2.0) \mathrm{h} / \mathrm{d}$ on weekdays and 7.3 (SD 3.9) h/d on weekends and days off. The PV $\leq 3$ group included 604 individuals, who played, on average, 1.3 (SD 1.1) h/d on weekdays and 2.4 (SD 2.2) h/d on weekends and days off. The difference on playing on weekends and days off was statistically significant between the groups (mean difference 4.9 (95\% CI 4.3-5.5).
The characteristics of the study population are described in Table 1 . The PV $>3$ group included more overweight individuals than the PV $\leq 3$ group $(P=.007)$, but there was no difference in the number of underweight individuals. In addition, those in the PV $>3$ group had, on average, 3.4\% higher body fat (95\% CI, 1.5-5.3\%; $P<.001), 3.1 \mathrm{~cm}$ larger waist circumference $(95 \% \mathrm{CI}$, $0.7-5.4 \mathrm{~cm} ; P=.011)$, and $2.1 \%$ less muscle mass $(95 \%$ CI, $1.0-3.1 \% ; P<.001$ ), as compared to those in the $\mathrm{PV} \leq 3$ group. The participants in the PV $>3$ group had poorer physical fitness, on average: $1.8 \mathrm{~kg}$ weaker grip strength $(95 \% \quad \mathrm{CI}, \quad 0.3-3.2 \mathrm{~kg} ; \quad P \quad=.017)$ and $3.2 \mathrm{~mL} / \mathrm{min} / \mathrm{kg}$ higher maximal oxygen uptake (95\% CI, $1.9-4.6 \mathrm{~mL} / \mathrm{min} / \mathrm{kg} ; P<.001)$. They also had less physical activity, as measured in MET min (median $=88$ in the $\mathrm{PV}>3$ group vs. median $=131$ in the $\mathrm{PV} \leq 3$ group, $P<.001)$. In the PV $>3$ group, $44 \%$ rated their physical fitness as poorer than that of their peers, but in the PV $\leq$ 3 group, only $18 \%$ did so $(P<.001)$. In the $\mathrm{PV}>3$ group, $12.8 \%$ rated their health as poorer than that of their peers, but in the $\mathrm{PV} \leq 3$ group, only $5.4 \%$ did so $(P=.001)$. Those who played a lot of video games also sat a lot; in the PV > 3 group, $69 \%$ of the participants sat for 5 $\mathrm{h} / \mathrm{d}$ or more during their leisure time, but in the $\mathrm{PV} \leq 3$ group, only $25 \%$ did so $(P<.001)$. Eating habits were also poorer in the PV $>3$ group; during the preceding week, those in this group ate vegetables and fruits less frequently (mean difference $0.5 ; 95 \% \mathrm{CI}, 0.3-0.8$ times per week; $P<.001)$ and drank sweetened soft drinks and energy drinks more often (mean difference 0.4; 95\% CI, 0.2-0.6 times per week; $P<.001$ ). In addition, those in the PV $>3$ group skipped breakfast more often than did those in the $\mathrm{PV} \leq 3$ group $(P<.001)$.

In the binary logistic regression analysis (Table 2), playing more video games on weekdays was significantly associated with all of the following: lower mean frequency of consuming vegetables and fruits $(\mathrm{OR}=0.83$; 95\% CI, 0.72-0.97), higher mean frequency of consuming sweetened soft drinks and energy drinks $(\mathrm{OR}=1.28$; 95\% CI, 1.06-1.55), higher leisure-time sitting ( $\mathrm{OR}=$ 1.40; 95\% CI, 1.28-1.52) and less leisure-time physical activity (OR $=1.94 ;$ 95\% CI, 1.29-2.91). This model explained $25.1 \%$ of the OR for high levels of video gaming.

\section{Discussion}

This population-based cross-sectional study of adolescent men mainly $17-18$ years old related to the associations that both physical activity and dietary habits have with the amount of video gaming on weekdays. Having low physical fitness, being obese, and having poor eating habits were more frequent among those who played video games more than $3 \mathrm{~h} / \mathrm{d}$ on weekdays. No difference was found in smoking and alcohol drinking. Low leisure-time physical 
Table 2 Factors associated with a high amount of video gaming on weekdays ( $>3 \mathrm{~h} / \mathrm{d}$ ) in the adolescent men ( $n=698)$ in the logistic regression analysis ${ }^{a}$

\begin{tabular}{|c|c|c|c|}
\hline Variables & Adjusted OR & $95 \% \mathrm{Cl}$ & $P$ Value \\
\hline \multicolumn{4}{|l|}{ Block 1: method = enter } \\
\hline Sitting during leisure time, hours & 1.40 & $1.28-1.52$ & $<.001$ \\
\hline \multicolumn{4}{|l|}{ Block 2: method = forward stepwise (LR) } \\
\hline Low leisure-time physical activity ${ }^{\mathrm{b}}$ (vs. $\geq 500$ MET-min weekly) & 1.94 & $1.29-2.91$ & .001 \\
\hline Mean consumption frequency of vegetables and fruits, $d / w k$ & 0.83 & $0.72-0.97$ & .014 \\
\hline $\begin{array}{l}\text { Mean consumption frequency of sweetened soft drinks and } \\
\text { energy drinks, } d / w k\end{array}$ & 1.28 & $1.06-1.55$ & .010 \\
\hline
\end{tabular}

activity, low frequency of consumption of vegetables and fruits, high consumption of sweetened soft drinks and energy drinks, and high amount of leisure sitting time explained one-fourth of the results.

High screen time is also associated with insufficient physical activity and higher sitting time, according to studies of 13- to 18-year-old boys and girls; in these studies, screen time included watching television, using a computer, playing video games, and using smartphones $[31,32]$. Video game playing has been negatively associated with physical activity among undergraduate men, especially among those who play online video games [33]. In addition, in a Spanish school-based study the adolescent boys who reported having weekly at least $4 \mathrm{~h}$ screen time more unlikely met the recommendation for moderate to vigorous physical activity [34]. This study's results indicate that there is a connection between high levels of video gaming and physical inactivity and sedentary behaviour. Researchers have reported that screen time is positively related to BMI in those aged 11-19 [33, 35, 36]. In addition, Ballard et al. [33] found a correlation between playing video games and high BMI. Although this study's results indicate that there is no difference in weight and BMI between the groups, the PV > 3 group included more obese $(\mathrm{BMI} \geq 30)$ adolescent men than the PV $\leq 3$ group. This study's association between a high amount of video gaming and poor selfrated health also supports the previous findings [37, 38].

Poor eating habits are also associated with playing video games. The results of a previous study of fourthgrade children show a positive association between video gaming and consumption of high-calorie and lownutrient foods [39]. Another study's results indicate that $2 \mathrm{~h} / \mathrm{d}$ or more of screen time is associated with increased energy intake [40], such that adolescents with more screen time consume more sugar-sweetened beverages $[32,41]$. Researchers have also suggested that those with high screen time tend to consume fewer vegetables and fruits $[31,32,40]$, and our study results indicate a similar association between high video gaming and lower consumption of vegetables and fruits.

This study's results indicate no association between alcohol consumption and the amount of video gaming, which supports the previous findings [42-44]. The previous findings on the association between smoking and video gaming are contradictory, with some researchers finding no relationship between smoking and video gaming $[42,44]$, but others finding the opposite [45].

The strengths of this research are its population-based design, which contained an entire age cohort of adolescent men at approximately 18 years old; its substantial data collection (questionnaire responses, measurements, and examinations); and its high compliance rate due to the data being collected during compulsory conscription. In addition, the measurements of body composition and physical performance were taken under controlled conditions. Those who did not complete the study questionnaire did not differ from the study participants with regards to perceived weight, self-rated health, sedentary behaviour, or anthropometric measures. However, those who did not complete the questionnaire were less likely to be students $(76 \%$ vs. $86 \%, P<.001)$ and had lower self-rated fitness $(29 \%$ vs. $38 \%, P=.001)$, as compared to their peers.

One limitation of this study is the lack of objective measurements of physical activity and time spent playing video games. In this study, we used self-reported measures, which may have led to overestimates of the participants' amount of overall physical activity $[46,47]$ or of the intensity of that activity [48]. We did not reveal the real amount of consumed vegetables and fruits (as well as other studied foods) with the used variable examining the average frequency of days when consumed vegetables and fruits, for example a study participant could eat fresh vegetables every day, but never cooked vegetables or fruits, thus having a mean frequency of 2.17 . The mean frequency was still used to reveal the overall consumption of vegetables and fruits, as it reflects the 
direction of consumed vegetables and fruits. The participants may have also encountered difficulties in recalling their food intake of last week. The study population consisted of adolescent men of specific age, which may limit the generalizability of the study results. Finally, this study was cross-sectional, so no conclusion regarding causality could be drawn.

\section{Conclusion}

In this population-based study of approximately 18 years old men, those who played video games more than 3 hours per day on weekdays, as compared to their peers, had lower levels of physical activity and were more likely to be obese. They also consumed less vegetables and fruits, and more sweetened soft drinks. Video gaming typically increases daily sitting time, as was also in this study, which affect harmful for health with other poor health behaviours. These preliminary results of this study fortify that video gaming is associated with detrimental health behaviour, which would be worth to take account with adolescent men, who play a lot on weekdays. Because physically less active $17-18$ years old men seemed to spend more time playing video games, it could be studied in the future whether video games could be used in physical activation of adolescent men. Prospective studies are also needed in order to investigate the causality of the correlation between video gaming and health behaviours in adolescent men.

\section{Abbreviations}

MET: Metabolic equivalent; BMl: Body mass index; PV > 3: Playing videogames $>3 \mathrm{~h} / \mathrm{d}$ on weekdays; $\mathrm{PV} \leq 3$ : Playing videogames $\leq 3 \mathrm{~h} / \mathrm{d}$ on weekdays

\section{Acknowledgements}

We would like to thank for the city of Oulu and Virpiniemi Sport Institute for their co-operation in this study.

\section{Authors' contributions}

TP and MS have been responsible for the data analysis and writing the first draft of the manuscript. RP, RK, MN and HE have provided contribution for the planning and implementation of the study, as well as for the writing of the manuscript. All authors have revised, read and accepted the final manuscript. The authors read and approved the final manuscript.

\section{Funding}

This study was funded by the Finnish Ministry of Education and Culture (DNRO 125/627/2009, 98/627/2010, 97/627/2011), Juho Vainio Foundation, Centre for Military Medicine Finland, Northern Ostrobothnia Hospital District, European Social Fund (project number S11580), European Regional Development Fund (70037/2010 and 70035/2011), the Finnish Cultural Foundation, and the Finnish Funding Agency for Technology and Innovation. The funding sources had no role in the study design, the collection, analysis, and interpretation of data, writing of the report or in the decision to submit the manuscript for publication.

\section{Availability of data and materials}

Data is available from the University of Oulu, for research collaborators who meet the criteria for accessing confidential data. Please, contact project center for further information: projectcenter@oulu.fi.

\section{Ethics approval and consent to participate}

The study was conducted according to the Declaration of Helsinki (2000), and was approved by the Ethical Committee of Northern Ostrobothnia Hospital District (ETTM123/2009). The study participants had the right to refuse to participate or withdraw from the study without any effects on their future health care or military service. Written informed consent was obtained.

Consent for publication

Not applicable.

\section{Competing interests}

The authors declare that they have no competing interests.

\section{Author details}

${ }^{1}$ Department of Sports and Exercise Medicine, Oulu Deaconess Institute Foundation sr, Albertinkatu 18A, P.O. Box 365, 90100 Oulu, Finland. ${ }^{2}$ Center for Life Course Health Research, Faculty of Medicine, University of Oulu, P.O. Box 5000, 90014 Oulu, Finland. ${ }^{3}$ Medical Research Center, Oulu University Hospital and University of Oulu, P.O. Box 5000, 90014 Oulu, Finland. ${ }^{4}$ Research Unit of Medical Imaging, Physics and Technology, Faculty of Medicine, University of Oulu, P.O. Box 8000, 90014 Oulu, Finland. ${ }^{5}$ Information Studies, Faculty of Humanities, University of Oulu, P.O. Box 8000, 90014 Oulu, Finland.

Received: 23 May 2019 Accepted: 12 March 2020

Published online: 30 March 2020

\section{References}

1. Janssen I, Leblanc AG. Systematic review of the health benefits of physical activity and fitness in school-aged children and youth. Int J Behav Nutr Phys Act. 2010;7(1):40

2. de Rezende LFM, Lopes MR, Rey-López JP, Matsudo VKR, do Carmo Luiz O. Sedentary behavior and health outcomes: an overview of systematic reviews. PLoS One. 2014;9(8):e105620.

3. Tremblay MS, LeBlanc AG, Kho ME, et al. Systematic review of sedentary behaviour and health indicators in school-aged children and youth. Int J Behav Nutr Phys Act. 2011;8(1):98.

4. Tremblay MS, Aubert S, Barnes JD, et al. Sedentary behavior research network (SBRN) - terminology consensus project process and outcome. Int J Behav Nutr Phys Act. 2017;14(1):75.

5. Falbe J, Rosner B, Willett WC, Sonneville KR, Hu FB, Filed AE. Adiposity and different types of screen time. Pediatrics. 2013;132(6):e1497-505.

6. Esposito N. A short and simple definition of what a videogame is. Vancouver: DiGRA 2005: Changing Views - Worlds in Play; 2005. http:// summit.sfu.ca/item/258. Accessed May 2019.

7. Unick JL, Lang W, Tate DF, Bond DS, Espeland MA, Wing RR. Objective estimates of physical activity and sedentary time among young adults. J Obes. 2017;2017(9257564):1-11.

8. Barnet TA, Kelly AS, Rohm Young D, et al. Findings from university hospital broaden understanding of obesity (sedentary behaviors in today's youth: approaches to the prevention and management of childhood obesity: a scientific statement from the American heart association). Med Devices Surg Technol Week. 2018;138:357.

9. Gentile D. Pathological video-game use among youth ages 8 to 18: a national study. Psychol Sci. 2009;20(5):594-602.

10. Männikkö N, Billieux J, Kääriäinen M. Problematic digital gaming behavior and its relation to the psychological, social and physical health of Finnish adolescents and young adults. J Behav Addict. 2015;4(4):281-8.

11. Rehbein F, Kleimann M, Mössle T. Prevalence and risk factors of video game dependency in adolescence: results of a German nationwide survey. Cyberpsychol Behav Soc Netw. 2010;13(3):269-77.

12. Lou D. Sedentary behaviors and youth: current trends and the impact on health. https://activelivingresearch.org/sites/activelivingresearch.org/files/ ALR_Brief_SedentaryBehavior_Jan2014.pdf. Published January 1, 2014. Accessed 19 Sept 2018.

13. World Health Organization. Global recommendations on physical activity for health 2010. https://www.who.int/dietphysicalactivity/global-PA-recs-2010. pdf. Accessed 15 Nov 2018. 
14. Currie C. Social determinants of health and well-being among young people: health behaviour in school-aged children (HBSC) study: international report from the 2009/2010 survey; 2012.

15. Special Eurobarometer 472. Sport and physical activity, vol. 472. Luxembourg: Publications Office; 2017. http://publications.europa.eu/ publication/manifestation_identifier/PUB NC0118171ENC.

16. The U.S. Department of Health and Human Services. Physical activity guidelines for Americans. In: A student guide to health: understanding the facts, trends, and challenges, vol. 2; 2018. p. 154-7.

17. Tremblay MS, Carson V, Chaput J, et al. Canadian 24-hour movement guidelines for children and youth: an integration of physical activity, sedentary behaviour, and sleep. Appl Physiol Nutr Metab. 2016;41(6 Suppl 3):311.

18. World Health Organization. Obesity and overweight. https://www.who.int/ news-room/fact-sheets/detail/obesity-and-overweight. Updated 2018. Accessed 16 Dec 2019

19. Inchley, J., Currie, D., Jewell, J., Breda, J., \& Barnekow, V. (2017). Adolescent obesity and related behaviours: trends and inequalities in the WHO European Region, 2002-2014. Copenhagen: World Health Organization Europe.

20. Borraccino A, Lemma $P$, Berchialla $P$, et al. Unhealthy food consumption in adolescence: role of sedentary behaviours and modifiers in 11-, 13- and 15year-old Italians. Eur J Public Health. 2016;26(4):650-6.

21. Pérez-Farinós N, Villar-Villalba C, López Sobaler AM, et al. The relationship between hours of sleep, screen time and frequency of food and drink consumption in Spain in the 2011 and 2013 ALADINO: a cross-sectional study. BMC Public Health. 2017;17(1):33-12.

22. Tammelin T. Physical activity from adolescence to adulthood and healthrelated fitness at age 31:cross-sectional and longitudinal analyses of the northern Finland birth cohort of 1966. 2003. http://jultika.oulu.fi/files/ isbn9514272331.pdf. Accessed Mar 2019.

23. Suija $K$, Timonen $M$, Suviola $M$, Jokelainen J, Järvelin $M$, Tammelin $T$. The association between physical fitness and depressive symptoms among young adults: results of the northern Finland 1966 birth cohort study. BMC Public Health. 2013;13:535.

24. Kaminsky LA, Montoye AHK. Physical activity and health: what is the best dose? J Am Heart Assoc. 2014;3(5):e001430.

25. Pyky R, Jauho A, Ahola R, et al. Profiles of sedentary and non-sedentary young men - a population-based MOPO study. BMC Public Health. 2015;15: 1164.

26. Vanhala ML, Laitinen J, Kaikkonen K, Keinänen-Kiukaanniemi S, Korpelainen R. Parental predictors of fruit and vegetable consumption in treatmentseeking overweight children. J Hum Nutr Diet. 2011;24(1):47-53.

27. Helakorpi S, Laitalainen E, Uutela A. Health behaviour and health among the Finnish adult population, spring 2009. Helsinki: National Institute for Health and Welfare (THL); 2010. Report 7/2010, 211 pages. ISBN 978-952-245-231-3 (print), ISBN 978-952-245-232-0 (pdf). In Finnish.

28. Vaara J, Ohrankämmen O. Physical performance of reservists; 2008. Finnish Defence Forces In Finnish.

29. Borodulin K, Lakka T, Laatikainen T, Laukkanen $R$, Kinnunen $H$, Jousilahti P. Associations of self-rated fitness and different types of leisure time physical activity with predicted aerobic fitness in 5979 Finnish adults. J Phys Act Health. 2004;1(2):142-53.

30. Väinämö K, Nissilä S, Mäkikallio T, Tulppo M, Röning J. Artificial neural networks for aerobic fitness approximation. ICNN. 2017;4:1939-44.

31. Christofaro DGD, De Andrade SM, Mesas AE, Fernandes RA, Farias Júnior JC. Higher screen time is associated with overweight, poor dietary habits and physical inactivity in Brazilian adolescents, mainly among girls. Eur J Sport Sci. 2016;16(4):498-506.

32. Kenney EL, Gortmaker SL. United States adolescents' television, computer, videogame, smartphone, and tablet use: associations with sugary drinks, sleep, physical activity, and obesity. J Pediatr. 2017;182:144-9.

33. Ballard M, Gray M, Reilly J, Noggle M. Correlates of video game screen time among males: body mass, physical activity, and other media use. Eat Behav. 2009;10(3):161-7.

34. Serrano-Sanchez JA, Martí-Trujillo S, Lera-Navarro A, Dorado-García C, González-Henríquez JJ, Sanchís-Moysi J. Associations between screen time and physical activity among Spanish adolescents. PLoS One. 2011;6(9): e24453.
35. Arango CM, Parra DC, Gómez LF, Lema L, Lobelo F, Ekelund U. Screen time, cardiorespiratory fitness and adiposity among school-age children from Monteria, Colombia. J Sci Med Sport. 2014;17(5):491-5.

36. Lajous $\mathrm{M}$, Chavarro J, Peterson KE, et al. Screen time and adiposity in adolescents in Mexico. Public Health Nutr. 2009;12(10):1938-45.

37. Sharma B, Cosme Chavez R, Jeong AS, Nam EW. Television viewing and its association with sedentary behaviors, self-rated heath and academic performance among secondary school students in Peru. Int J Environ Res Public Health. 2017;14(4):383.

38. Shiue I. Self and environmental exposures to drinking, smoking, gambling or video game addiction are associated with adult hypertension, heart and cerebrovascular diseases, allergy, self-rated health and happiness: Japanese general social survey, 2010. Int J Cardiol. 2015;181:403-12.

39. Pentz MA, Spruijt-Metz D, Chou CP, Riggs NR. High calorie, low nutrient food/beverage intake and video gaming in children as potential signals for addictive behavior. Int J Environ Res Public Health. 2011;8(12):4406-24

40. Shang L, Wang J, O'Loughlin J, et al. Screen time is associated with dietary intake in overweight Canadian children. Prev Med Rep. 2015;2:265-9.

41. Lowry R, Michael S, Demissie Z, Kann L, Galuska DA. Associations of physical activity and sedentary behaviors with dietary behaviors among US high school students. J Obes. 2015;2015:876524.

42. Desai RA, Krishnan-Sarin S, Cavallo D, Potenza MN. Video-gaming among high school students: health correlates, gender differences, and problematic gaming. Pediatrics. 2010;126(6):1414.

43. Walther B, Morgenstern M, Hanewinkel R. Co-occurrence of addictive behaviours: personality factors related to substance use, gambling and computer gaming. Eur Addict Res. 2012;18(4):167-74.

44. Carson V, Pickett W, Janssen I. Screen time and risk behaviors in 10- to 16year-old Canadian youth. Prev Med. 2011;52(2):99-103.

45. Spilková J, Chomynová P, Csémy L. Predictors of excessive use of social media and excessive online gaming in Czech teenagers. J Behav Addict. 2017;6(4):611-9.

46. Hagstromer M, Ainsworth BE, Oja P, Sjostrom M. Comparison of a subjective and an objective measure of physical activity in a population sample. J Phys Act Health. 2010:7(4):541-50.

47. Shephard RJ. Limits to the measurement of habitual physical activity by questionnaires. Br J Sports Med. 2003:37(3):197-206 discussion 206.

48. Prince SA, Adamo KB, Hamel ME, Hardt J, Connor Gorber S, Tremblay M. A comparison of direct versus self-report measures for assessing physical activity in adults: a systematic review. Int J Behav Nutr Phys Act. 2008;5:56.

\section{Publisher's Note}

Springer Nature remains neutral with regard to jurisdictional claims in published maps and institutional affiliations.
Ready to submit your research? Choose BMC and benefit from:

- fast, convenient online submission

- thorough peer review by experienced researchers in your field

- rapid publication on acceptance

- support for research data, including large and complex data types

- gold Open Access which fosters wider collaboration and increased citations

- maximum visibility for your research: over $100 \mathrm{M}$ website views per year

At $\mathrm{BMC}$, research is always in progress.

Learn more biomedcentral.com/submission 